\title{
Temporal Model for Assessing the Quality of Public Services
}

\author{
Larisa Bulysheva \\ Old Dominion University \\ Norfolk, USA \\ lbulyshe@odu.edu \\ Mikhail Kataev \\ Tomsk state University of control systems and \\ Radioelectronics \\ Tomsk, Russia \\ kataev.m@,sibmail.com
}

\author{
Natalia Loseva \\ Tomsk branch of the Social insurance Fund \\ Tomsk, Russia \\ lonat@bk.ru
}

\begin{abstract}
The material about the use of business processes to determine the quality of receiving services in a public institution is presents in article. It is proposed to take into account when obtaining a quality not only qualitative assessments, which are connected with the expert assessment and customer opinion and quantitative related to the timing of execution of business processes by employees. Shown mathematical expressions that allow build an automated quality evaluation system.
\end{abstract}

Keywords— public institution, quality, business-process

\section{INTRODUCTION}

The basis of many government agencies is the provision of various services, which are regulate for quality. Today's complex and dynamic environment requires from the institutions to constantly improving its management systems to maintain quality provision of services regulations level. One of the modern trends of the method of management of different organizations is the use of a process-oriented approach, which is base on business processes. The advantage of this approach is: 1) orientation activities of companies in the consumer services; 2) director's leadership in all processes of the organization; 3) involvement of employees in the management process; 4) a systematic approach to management based on business processes); 5) continuous improvement of management system; 6) making decisions based on actual figures obtained chain business processes [1-3].

Existing approaches to control based generally on the use of different vertical organizational structure of the institution. In this case, the management is carried out by separate elements of the organization (departments) and their interaction through officials (heads of departments) and by the structural units of a lower level. The disadvantages of this approach to the management of the activities of the institution are the following:

1) Any work to provide the client with the services split into separate, usually unrelated fragments that are associated with the structure of institutions, which complicates the controllability and handling;

2) Lack of responsible for the final result, as the work is formally fragmented, making it impossible to assess the quality and availability of each piece, especially if the fragments are dependent on each other;

3) Lack of orientation of the obtained result to the client when there is a build task result from separate fragments;

4) Very complex problem to develop information support of decision-making.
That is the process-oriented approach allows us to build on the business process chain is a sequence of actions leading to the provision of services of value to customers. Under a process-oriented approach to the management of public institutions will understand the management system based on business processes. In this approach, the institution is considered as a system consisting of chains of business processes, which is the service provided to the client. A business process is a set of different functions, each of which defines the types of activities that in aggregate allows obtaining the result (service) with a specified quality.

\section{BUSINESS PROCESSES OF THE STATE INSTITUTION}

Note that existing information systems [4] based on outdated principles of management that involves the formation of paper statements, processing the received information manually and analysis managers. Modern technologies of electronic document allow only for certain class of problems to obtain efficient solutions. However, even the use of such technologies can not provide the proper quality control as related to decision making, the leader based on his skills and intuition. Improving the quality and efficiency of the processes of providing public services related to implementation of a new type of management approaches based on a process-oriented approach. Individual elements of this task for a government agency Social Insurance Fund [SIF] (http://www.fss.ru) is given in this article.

Among the many business processes, SIF central is "the Reception of the report 4SIF". This business process is a public service to receive report (calculation) provided by the companies and persons who entered into a legal relationship on compulsory social insurance against temporary disability and in connection with motherhood. The insurant generates a report and transmits it to the SIF in person to the specialist by mail or e-mail (see Fig. 1 direction 1). After verification of the report specialist, the error correction by the insurant (if any), a report signed and sent to other specialists for treatment (see Fig. 1 direction 2), From the description it is seen that in certain cases, a business process is linear, and when conditions change (error) becomes the iteration (see Fig. 1 direction 1-2-3-1).

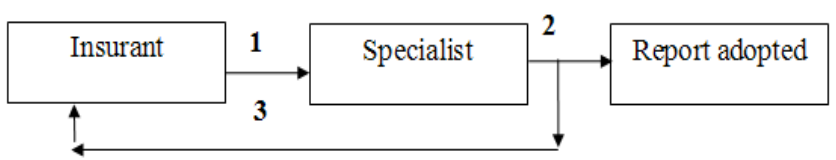

Fig. 1. Business process of the "the Reception of the report 4SIF"

The use of mathematical models of service delivery in a public institution, which is base on business processes, enables a systematic evaluation of management decisions 
taken under the influence of external and internal environment. The peculiarity of the business processes of the public institutions is their unequivocal certainty on the set of functions, sequences and a clear customer focus at a given quality. Optimization of the relations between functions of a business process allows to achieving a given level of quality, to optimize time parameters and choose the best option to achieve quality under the influence of external and internal factors.

The mathematical model relies on the function of the tactical level as well as detailed information that occurs at the operational level leads to a significant number of random parameters (come - not came, brought report, not brought report, was late for 5 minutes. etc.). The description of the behavior of a business process in time, the adoption service, is base on additive temporal model. Model the business process in the provision of services in a public institution may be represent by a set of parameters:

$$
\mathrm{BP}=<\mathrm{T}, \mathrm{I}>\text {, }
$$

where $\mathrm{T}$ is a specified, regular time execution of a business process, BP (Business Process); I - the set of information required to implement the business process.

\section{DESCRIPTION OF THE PROPOSED MODEL}

The analysis of the literature on approaches to assessing the quality of services showed that most of them are base on expert assessments and the results of the questionnaire of monitoring and surveys [5-7]. These approaches, in General, can show a realistic assessment of the situation with the quality of services, but stretched in time, depend on the qualifications of the experts and are qualitative in nature. Most importantly, the results of these studies are poorly applicable in practice due to their quality and the significant flow in time of the event and its assessment, which does not apply to management activities, the solution of current problems.

The time spent by the client is one of the parts quality, which is a state institution. However, this time is not amenable to automated commit and subsequent analysis. Therefore, the main part of the evaluation of the quality of client services possible for the automated commit is the work of a specialist. In this respect, the quality of the provision of the same services in a public institution can be estimated as the time:

$$
\mathrm{T}(\mathrm{k})=\sum_{\mathrm{i} j}^{\mathrm{MN}} \mathrm{t}(\mathrm{i}, \mathrm{j}, \mathrm{k}) /(\mathrm{N} \cdot \mathrm{M}),
$$

where $t(i, j, k)$ is the time of rendering of the state service of the $\mathrm{i}$-th customer $(\mathrm{i}=1, \ldots, \mathrm{M}) \mathrm{k}$-th expert and $\mathrm{j}$ is the number of functions required to receive the service $(j=1, \ldots, N)$.

Analyzing the expression (2) can determine the condition under which a high quality of service in a public institution, which is associated with the minimization of time expenditures for the implementation of each function of the business process:

$$
\mathrm{K} \rightarrow \min \left(\mathrm{T}_{\Sigma}-\mathrm{Tr}\right)
$$

here $\mathrm{T} \sum=\sum \mathrm{T}(\mathrm{k}) / \mathrm{K}$ - real time provision of services by all $\mathrm{K}$ experts institutions, $\mathrm{Tr}$ - order time specified by law.

From (3) it is seen that the estimation of time costs for the provision of services allows us to estimate the activity of the whole institution in General and to assess each separately (considering the expression $(\mathrm{T}(\mathrm{k})-\mathrm{Tr})$ ). In this regard, the quality of the provision of services in a public institution is easy to assess on the basis of (3):

$$
\mathrm{Q}=(\mathrm{T}-\mathrm{Tr}) / \mathrm{Tr} \text {. }
$$

Evaluating the expression (4) it can be noted that for the evaluation of the quality of provision of certain services in a public institution, you can use the index $\mathrm{Q}$. Then the $\mathrm{Q}$ tends to the value "zero» $(\mathrm{Q} \approx 0)$, the activities of the institution determined by the rules more indicators. If $\mathrm{Q}>0$, then this means that the display quality is decreased and the larger the value, the lower the quality of the service. Considering the time indicators carry out the functions of the business process, we can identify the source of performance and reduce a particular artist that function. A case where $\mathrm{Q}<0$ is important for analysis as a systematic reduction in run-time functions with respect to routine, can not speak of success, but rather of the failure of certain tasks function.

\section{CONCLUSION}

The paper proposes a methodology based on business processes for the administrative monitoring of the activities of employees in the service delivery process. The methodology includes two components: qualitative and quantitative, that allows to reveal features, including faults, temporal organization of work for every specialist, to assess the success of the employee in the position.

\section{ACKNOWLEDGMENT}

This article is designed as part of the national project of the Ministry of Education and Science of the Russian Federation № 8.8184.2017/8.9 "Methodology for the creation of systems of energy-generating and energy-transforming devices for ground and airborne ground, space and underwater-based systems".

\section{REFERENCES}

[1] F.I. Peregudov, F.P. Tarasenko Fundamentals of systems analysis. Tomsk: Izd-vo nauch.-tech. lit., 1997. 389 p.

[2] V.N.Burkov, Korgin N., Novikov D.A. Introduction to the theory of organizational systems management, M.: Librokom, 2009, 264 p.

[3] V.V. Repin Process approach to management. Modeling business processes, M.: Ria "Standards and quality", 2005, 314 p.

[4] M.Yu. Kataev, L.A. Bulysheva, A.A. Emelyanenko, V.A. Emelyanenko "Enterprise systems in Russia: 1992-2012", Enterprise Information Systems, vol. 7, N. 2, pp.169-186, 2013

[5] M.A. Louly "A goal programming model for staff scheduling at a telecommunications center" Journal of Mathematical Modeling and Algorithms in Operations Research, vol. 12, N .2, p. 167-178, 2013

[6] S.Y. Jang, J. Park, N. Park “An Integrated decision support system for FMS production planning and scheduling problems" International Journal of Advanced Manufacturing Technology, vol.11, pp. 101-110, 1996

[7] M. Basnet "Scheduling and control of Flexible manufacturing systems: A critical review" International Journal of Computer Integrated Manufacturing, vol. 7, N. 6, pp. 340-355, 1994 